\title{
Dysphagia due to DISH-related anterior osteophytes: DISHphagia!!
}

\author{
Jaslovleen Kaur, ${ }^{1}$ Jagandeep Singh Virk ${ }^{2}$
}

'Department of Neurology, DMC LUDHIANA, Ludhiana, Punjab, India

${ }^{2}$ Department of Orthopaedics, Government Medical College and Hospital, Chandigarh,

Punjab, India

\section{Correspondence to}

Dr Jaslovleen Kaur,

jaslovleen@gmail.com

Accepted 7 October 2017

\section{DESCRIPTION}

Anterior cervical osteophytes are commonly associated with degenerative spine in elderly people. The complications that arise due to the mechanical compression of cervical osteophytes are dysphagia, dysphonia and dyspnoea. The usual causes are osteoarthritis, ankylosing spondylitis and diffuse

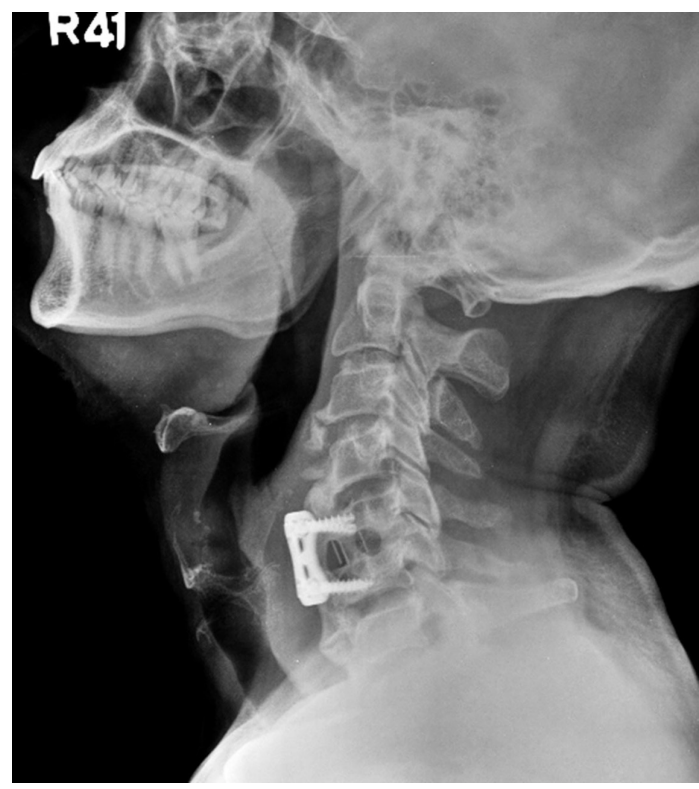

Figure 1 Radiograph of the neck (lateral view) showing large anterior cervical osteophytes at the level of C3, C4, C5, C6. Also, an anterior cervical metallic plate with screw fixation can be appreciated in situ at the level of the C5-C6 vertebral body. idiopathic spinal hyperostosis (DISH). Other causes are trauma, acromegaly, ochronosis, fluorosis and hypoparathyroidism. ${ }^{1}$ Surgical resection of osteophytes results in excellent relief of symptoms, but patients have a tendency for recurrence of osteophytes. $^{2}$ We present here a case of dysphagia and dysphonia due to osteophyte recurrence in a postsurgical case of DISH.

A 63-year-old man was admitted with progressive dysphagia, hoarseness of voice and neck pain for 3 months. His history began with neck and right arm pain 2 years back for which he consulted a spine surgeon, where he was diagnosed with C5-C6 herniated cervical disc causing root compression because of underlying DISH. His chief complaints were severe neck pain with radiation to lateral aspect of his right arm. Patient gave no history of hand clumsiness or gait imbalance. On neurological examination, patient was having no motor or sensory deficit with normal deep tendon reflexes. His plantar reflex was flexor. Radiographs, CT and MRI of the cervical spine were subsequently conducted. MRI reported a final impression of cervical spondylosis, disco-osteophytic bulge with paracentral disc protrusion at C5-C6 level causing significant compression of the cord with myelomalacia and focal canal stenosis at this level. An overall picture of DISH was also appreciated. Following this, he underwent C5-C6 anterior cervical discectomy and fusion. Anterior osteophytes at C3-C4 level were also noted in imaging but their size was small and considered insignificant to the patient's symptoms with which the patient had presented to us. Thus, anterior osteophytes at C3-C4 level were

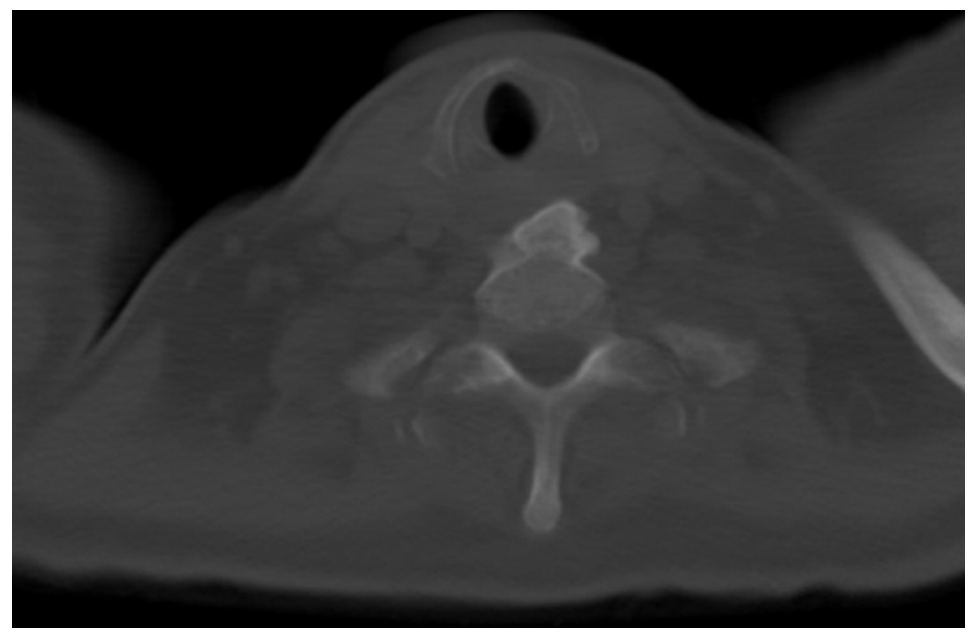

Figure 2 CT scan of neck and chest (axial view) suggesting large anterior bridging osteophytes at the level of C4-C5 vertebra causing indentation on the posterior pharyngeal wall in the region of upper oesophagus. 
not excised. Postoperatively, he was asymptomatic over the next 2 years. To evaluate for his recently developed symptoms, radiographs of the cervical spine were done (figure 1). Large-sized anterior cervical osteophytes were well appreciated in a characteristic 'flowing candle-wax' appearance. Radiographs, however, did not reveal any cage displacement or hardware dislodgement that could explain the possible symptoms. CT chest and neck revealed prominent anterior osteophytes compressing on

\section{Learning points}

- Dysphagia secondary to cervical osteophytes in patients of diffuse idiopathic spinal hyperostosis (DISH) is an overall rare event. In DISH, symptoms such as dysphagia, dysphonia, dyspnoea and obstructive sleep apnoea are because of anterior osteophytes as has been observed in most case reports. It is rare to see posterior osteophytes contributing to symptoms such as in this case during the first time when the patient presented with cervical disc bulge with osteophytic involvement leading to cervical radiculopathy.

- This is a surgically treatable condition and the majority of patients treated recover successfully, but patients need to be counselled regarding the high chances of progression or recurrence of osteophytes.

- Observing a periodic follow-up is crucial to look for early signs of oesophageal/tracheal compression. adjacent wall of oesophagus, narrowing the lumen (figure 2). Patient was subsequently scheduled for surgery and anterior osteophytes were excised uising the anterior cervical approach. After surgery, patient had immediate relief of his symptoms. Patient is now on our regular follow-up with no signs and symptoms of dysphagia or dysphonia. Surgical resection of osteophytes in patients with DISH results in excellent symptom relief but simultaneously there is a high likelihood of the recurrence of osteophytes. Therefore, subtle signs such as dysphagia and dysphonia should be recognised early and maintaining a regular follow-up is crucial in patients of DISH.

Contributors JSV did the conception and design, interpreted the data, conducted radiological diagnosis and designed and structured the report. JK conducted acquisition of data and interpretation of data.

Competing interests None declared.

Patient consent Obtained.

Provenance and peer review Not commissioned; externally peer reviewed.

(C) BMJ Publishing Group Ltd (unless otherwise stated in the text of the article) 2017. All rights reserved. No commercial use is permitted unless otherwise expressly granted.

\section{REFERENCES}

1 Hwang JS, Chough CK, Joo WI. Giant anterior cervical osteophyte leading to Dysphagia. Korean J Spine 2013;10:200-2.

2 Miyamoto K, Sugiyama S, Hosoe H, et al. Postsurgical recurrence of osteophytes causing dysphagia in patients with diffuse idiopathic skeletal hyperostosis. Eur Spine J 2009;18:1652-8.

Copyright 2017 BMJ Publishing Group. All rights reserved. For permission to reuse any of this content visit

http://group.bmj.com/group/rights-licensing/permissions.

BMJ Case Report Fellows may re-use this article for personal use and teaching without any further permission.

Become a Fellow of BMJ Case Reports today and you can:

- Submit as many cases as you like

- Enjoy fast sympathetic peer review and rapid publication of accepted articles

- Access all the published articles

- Re-use any of the published material for personal use and teaching without further permission

For information on Institutional Fellowships contact consortiasales@bmjgroup.com

Visit casereports.bmj.com for more articles like this and to become a Fellow 